Int. J. Dev. Biol. 59: 211-216 (2015)

doi: $10.1387 / \mathrm{ijdb} .150172 \mathrm{mz}$

\title{
3D culture of ovarian follicles: a system towards their engineering?
}

\author{
MAURIZIO ZUCCOTTI*,1, VALERIA MERICO², PAOLA REBUZZINI², MARTINA BELLI ${ }^{2}$, GIULIA VIGONE², \\ FRANCESCA MULAS ${ }^{3}$, LORENZO FASSINA ${ }^{3,4}$, WASCO WRUCK ${ }^{5}$, JAMES ADJAYE ${ }^{5,6}$, \\ RICCARDO BELLAZZI ${ }^{3}$ and SILVIA GARAGNA*,2,4
}

\begin{abstract}
${ }^{1}$ Sezione di Anatomia, Istologia ed Embriologia, Dipartimento di Scienze Biomediche, Biotecnologiche e Traslazionali (S.Bi.Bi.T.), Università degli Studi di Parma, Italy, ${ }^{2}$ Laboratorio di Biologia dello Sviluppo, Dipartimento di Biologia e Biotecnologie 'Lazzaro Spallanzani', Università degli Studi di Pavia, Italy, ${ }^{3}$ Dipartimento di Ingegneria Industriale e dell'Informazione, Università degli Studi di Pavia, Pavia, Italy, ${ }^{4}$ Centro di Ingegneria Tissutale, Università degli Studi di Pavia, Italy, ${ }^{5}$ Institute for Stem Cell Research and Regenerative Medicine, Medical Faculty, Heinrich Heine University, Düsseldorf, Germany and ${ }^{6}$ Molecular Embryology and Aging Group, Department of Vertebrate Genomics. Max-Planck Institute for Molecular Genetics, Berlin, Germany.
\end{abstract}

\begin{abstract}
Infertility in women is a health priority. Designing a robust culture protocol capable of attaining complete follicle growth is an exciting challenge, for its potential clinical applications, but also as a model to observe and closely study the sequence of molecular events that lie behind the intricate relationship existing between the oocyte and surrounding follicle cells. Here, we describe the procedures used to maintain the ovarian follicle 3D architecture employing a variety of in vitro systems and several types of matrices. Collagen and alginate are the matrices that led to better results, including proof-of-concept of full-term development. Pioneer in its kind, these studies underlie the drawbacks encountered and the need for a culture system that allows more quantitative analyses and predictions, projecting the culture of the ovarian follicle into the realm of tissue engineering.
\end{abstract}

KEY WORDS: Ovarian follicle, 3D culture, matrix, collagen, alginate, tissue engineering

\section{Introduction}

Women infertility is a health priority that has several causes including X-chromosome abnormalities, autosomal genetic pathologies, environmental hazards, bilateral ovariectomy, and, above all, it may be the result of cytotoxic therapies required for malignant and autoimmune diseases. Impressively, more than one-third of women (including children, teens and young women) diagnosed with cancer and exposed to chemo/radio therapy are under the risk of developing ovarian failure, sterility and early menopause as common alongside effects (Anchan and Ginsburg, 2010). In numbers, this translates into $\mathrm{a} \sim 100.000$ /year or $\sim 1.000 .000$ /year women patients that, in countries like Italy or in the USA respectively, are treated for cancer and may develop infertility. Chemotherapy and radiation irreversibly damage the ovary inducing stromal fibrosis, loss of early follicles resulting in premature ovarian failure. Improvements in the diagnosis and treatment of childhood, adolescent and adult tumours has led to a marked amelioration of the recovery and survival rates, raising the need for developing strategies of fertility preservation that precede the therapeutic intervention and that neither delay nor interfere with the protocol required for the patient's survival.

An increasing number of women are offered the option of cryopreserving their ovarian tissue prior to the therapeutic treatment, although, at this time, this opportunity envisages the transplantation of the frozen-thawed tissue, a complex protocol that is not appropriate to all patients and that may lead to the reintroduction of cancer cells, as for patients diagnosed with leukemia (Meirow et al., 2008).

Considering the important improvements that have been made in the development of in vitro protocols of follicle maturation, the culture of ovarian follicles isolated from stored ovarian tissue may become a valid alternative. Thus, designing a robust culture pro-

Abbreviations used in this paper: 3D, three dimension.

\footnotetext{
*Address correspondence to: Maurizio Zuccotti. Sezione di Anatomia, Istologia ed Embriologia, Dipartimento di Scienze Biomediche, Biotecnologiche eTraslazionali (S.Bi.Bi.T.), Università degli Studi di Parma, Via Volturno, 39 - 43125, Parma, Italy. E-mail: maurizio.zuccotti@unipr.it or

Silvia Garagna. Laboratorio di Biologia dello Sviluppo, Dipartimento di Biologia e Biotecnologie 'Lazzaro Spallanzani', Università degli Studi di Pavia, Via Ferrata 9 - 27100, Pavia, Italy. E-mail: silvia.garagna@unipv.it
}

Accepted: 28 May 2015.

ISSN: Online 1696-3547, Print 0214-6282 
tocol capable of attaining complete follicle growth, ideally from the tiny primordial to the fully-grown follicle, is an exciting challenge for its potential clinical applications. Also, a culture system able to maintain the three-dimensional (3D) follicle architecture represents a model to observe and closely study the sequence of molecular events that lay behind the intricate biochemical and biophysical relationship existing between oocyte and surrounding follicle cells, an integrity of connections that is necessary during follicle growth to the acquisition of the oocyte developmental competence ( $\mathrm{Li}$ and Albertini, 2013).

The main culture procedures adopted envisage the growth of follicles either with their somatic component adhering to the bottom of the Petri dish or embedded within a supporting scaffold (i.e., matrix) or a sequential combination of the two. When follicles are cultured in the absence of a matrix, although still partially keeping their 3D organisation, their somatic component tends to flatten and spread on the under surface. Whilst this latter procedure remains the most widely employed and has a history of success, several other culture systems that use matrices throughout the culture period have been experimented with promising results.

In this short review, we describe the main matrix culture systems designed to maintain the 3D architecture of the ovarian follicle, the principal results obtained and drawbacks encountered. Also, we underlay the need, at this stage, for a culture system that allows more quantitative analyses and predictions, an objective that could be achieved through a multidisciplinary approach.

\section{Follicle growth in matrix culture systems}

Introducing a third dimension in a cell culture procedure requires the design of scaffolds for supporting the organisation of the tissue that cells are contributing to build up and, furthermore, a complex that regulates the exchange of nutrients and waste products. $A$ variety of culture setups have been developed aimed at maintaining the architecture of the follicle, with the somatic component growing in all directions around the oocyte. Most of these systems imply the use of a biomaterials to create a matrix in which the follicle is either embedded or encapsulated and sustained throughout its growth (Fig. 1). Different biomaterials, either natural or synthetic, have been tested, each with advantages and drawbacks.

Natural matrices have the advantage of being highly biocompatible and bioactive (i.e., they enter into a functional contact with cells in culture), but have the disadvantage that their mechanical and physical properties are difficult to model and present a high variability between batches. On the contrary, synthetic matrices are more standard in composition and can be designed with the desired properties to meet each specific demand, although the apparent lack of bioactivity restricts their use to mere scaffolds for cell culture. Two are the main natural matrices tested, collagen and alginate.

Collagen is a natural component of the extracellular matrix (ECM), very flexible and elastic, involved in many cellular processes and, historically, the first experimented biomaterial. Several culture protocols have been developed using either a layer of sole collagen matrix, a collagen matrix enriched with ECM proteins (i.e., fibronectin and laminin) and RGD (arginine-glycine-aspartate) sequences, or collagen microdrops. Since its first use in the late ' 80 s, collagen was proved capable of sustaining follicle growth, follicle cells proliferation and oocyte maturation in both 2D (Eppig and
Schroeder, 1989) and 3D (Torrance et al., 1989) culture protocols.

Torrance and co-workers first introduced the idea of maintaining the 3D architecture during follicle culture: two-layers preantral follicles, isolated from 10-day-old mice, were embedded in a collagengel solution and cultured for fourteen days until they developed to a multilaminar complex, although without an antrum (Torrance et al., 1989). An improvement was achieved by transferring preantral oocytes surrounded by two-three layers of granulosa cells onto a film of collagen already polymerised and covered with a second coating of collagen solution (Gomes et al., 1999). When the latter polymerised, the follicles were cultured for further six days. Compared to a bi-dimensional culture that developed into a flattened follicle with distorted morphology, follicles cultured in collagen grew preserving a better architecture, more homogenous equatorial diameter and spherical shape, a basal lamina integrity and showed a reduced follicle cells loss.

Using the same embedding procedure, a further refinement was obtained using a two-steps culture protocol for both murine and human immature small antral follicles (Vanhoutte et al., 2009). Initially, follicles were pre-matured in collagen for $24 \mathrm{hr}$ in the presence of phosphodiesterase 3-inhibitor that prevented meiotic resumption and allowed completion of cytoplasmic maturation: then, they were matured with a standard in vitro maturation (IVM) protocol. At the end of this period, trans-zonal projections with active gap junctions were observed, suggesting the maintenance of a functional communication between oocyte and the somatic companion cells. These oocytes attained meiotic competence and, once fertilised, completed preimplantation development (in vitro vs. in vivo grown follicles mouse blastocysts, $43 \%$ vs. $70 \%$; human blastocysts, $55.6 \%$ vs. 55.8\%) (Vanhoutte et al., 2009).

A turning point was reached using a three-step culture protocol that led to the birth of live mouse offspring (Mochida et al., 2013). Primary and early secondary follicles isolated from 6-day-old mouse ovaries were first cultured for nine days embedded in a collagen gel, then they were moved on a collagen-coated membrane (Transwell-COL) and cultured for further eight days. Depending on the original size, $9.9 \%(60-70 \mu \mathrm{m}$ in diameter), 33.5\% $(70-80$ $\mu \mathrm{m})$ and $61.6 \%(80-95 \mu \mathrm{m})$ follicles with an antral-like cavity were harvested on day seventeen of culture and matured to metaphase II (MII) in IVM medium ( 18\%). Fertilised MII oocytes reached the 4-cell stage $(30.3 \%)$ and, when transferred to pseudo-pregnant females, two developed to term. Although the number of MII oocytes that reached full term was low, this study consolidates the concept that the culture of very early follicles can be successfully obtained in a 3D culture system.

The 3D culture of human follicles has been intermittently tested with interesting, although yet preliminary, outcomes. In a pilot morphological study, primordial/primary follicles, isolated from fresh or frozen-thawed ovarian tissue, were embedded in a collagen gel and cultured for $24 \mathrm{hr}$ obtaining an increased number of somatic cells and a larger follicle size (Abir et at., 1999). In a further work, human follicle cell-free oocytes arrested at the germinal vesicle (GV) or metaphase I (MI) were embedded in a 3D collagen matrix together with their isolated follicle cells and matured until they reached the MII stage (Combelles et al., 2005). While the maturation rate to MII was similar to that of control denuded oocytes, those co-cultured in the 3D system displayed increased MAPK activity, although identical maturation-promoting factor (MPF) levels (Combelles et al., 2005). 
A collagen-based demineralised bone matrix was used to grow follicle cells isolated from antral oocytes (>70 $\mu \mathrm{m}$ in diameter) (Ma et al., 2007). After $24 \mathrm{hr}$ culture, the isolated oocytes were added to the scaffold and cultured for further $14 \mathrm{hr}$. The porous texture allowed cumulus cells proliferation and facilitated the diffusion of nutrients. In particular, the pattern of distribution of the cortical granules, the levels of MPF and the zona pellucida hardening were similar to those of in vivo matured oocytes. Moreover, when compared to control denuded oocytes matured in microdrops, good maturation (MII 93.4\% ctrl vs. 93.3\% in microdrops) and developmental (blastocysts $79.5 \%$ ctrl vs. $30.9 \%$ in microdrops) rates were obtained.

In summary, although these studies have achieved key results, including full-term development, a robust protocol that allows consistent outcomes is not yet available and three main drawbacks of the use of a collagen matrix have emerged. First, its preparation has not yet been standardised, since collagen is frequently prepared directly in the laboratory thus producing utmost variability. Second, the temperature, above $37^{\circ} \mathrm{C}$, required to maintain collagen at the liquid phase at the time when follicles are embedded and, third, at the end of the culture period collagen is treated with collagenase to release the enclosed follicles, hence undertaking the risk of digesting also the endogenous collagen present in the basal lamina.

Alginate, another natural matrix tested, is a polysaccharide with properties of biocompatibility and permeability, which can be moulded into round shaped beads filled with cells. When the cell-alginate solution gets in contact with a calcium solution, beads are formed. Thus, single ovarian follicles can be encapsulated in alginate beads and grown in a 3D environment. To date, different groups have succeeded in culturing two- or multi-layered follicles of 100-130 $\mu \mathrm{m}$ and 150-180 $\mu \mathrm{m}$ in diameter, respectively, in a matrix of alginate alone (Pangas et al., 2003; Heise et al., 2005; Xu et al., 2006a,b; West et al., 2007; Parrish et al., 2011; Tagler et al., 2013) or combined with fibrin (Jin et al., 2010; Shikanov et al., 2009, 2011b) or ECM proteins (Kreeger et al., 2006). These studies achieved important results, including the recording of the luteinisation and ovulation events (Skory et al., 2015) and the birth of live and fertile mice (Xu et al., 2006a). In this latter work, single multi-layered secondary follicles, isolated from 16-day-old female mice, were encapsulated into beads of $1.5 \%$ alginate and matured in $100 \mu \mathrm{l} \alpha$-MEM for eight days until they reached the antral stage. The granulosa cells proliferated and actively secreted hormones such as estradiol, androstenedione and progesterone, which increased linearly during culture as expected for the in vivo counterpart. The resulting cumulus-oocyte-complexes were enzymatically released with alginate lyase, the antral oocytes denuded and further cultured for $16 \mathrm{hr}$ until they reached the MII phase $(70.9 \%)$. Upon in vitro fertilisation, $68.2 \%$ reached the 1 -cell stage and, when twenty of these were transferred to pseudopregnant females, four reached full-term development. This work proves that encapsulation inside an alginate bead allows follicle growth in diameter and acquisition of morphological and functional features of antral follicles grown within the ovary. The oocytes however resume meiosis and acquire developmental competence with lower rates compared to controls. To address this problem, Mainigi and colleagues cultured early secondary follicles encapsulated into $0.25 \%$ alginate beads up to the antral stage (Mainigi et al., 2011). They confirmed that the alginate culture sustains follicle growth and oocyte maturation, but oocytes were seriously compromised, with disorganised and misaligned meiotic spindles, a non-uniform distribution of cortical granules and undermined fertilisation and developmental competence.

In all the studies described above, oocytes were co-cultured with their companion cumulus cells, without the surrounding theca cells that enclose the ovarian follicle and, if present in vitro, would help the maintenance of a compact spherical shape. With this in mind, Sittadjody and colleagues encapsulated granulosa cells in single alginate beads that were then further coated with a layer of poly-L-ornithine and mixed with theca cells suspended in alginate and encapsulated again in alginate using a micro-fluidic device (Sit-

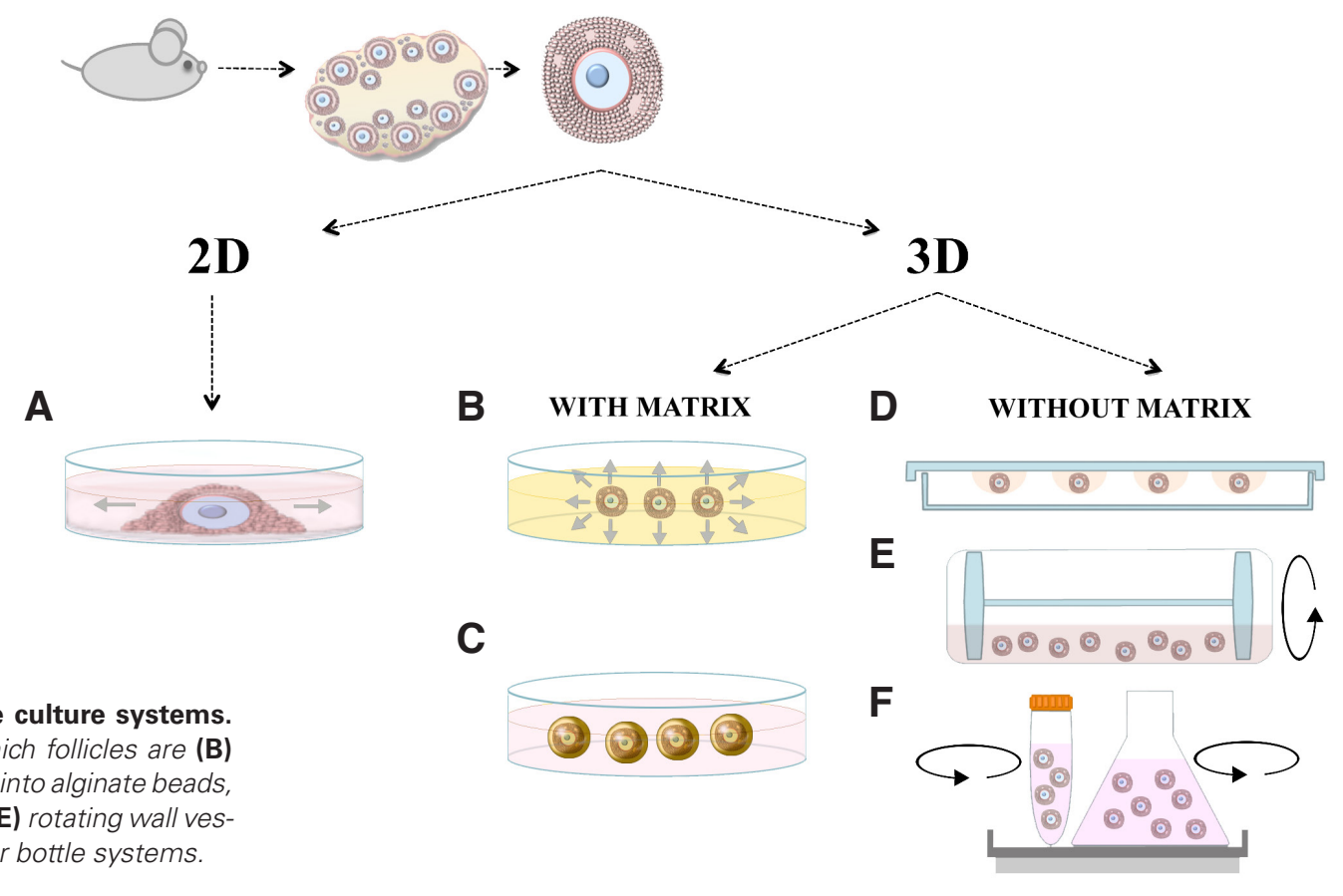

Fig. 1. Summary of the main follicle culture systems. (A) 2D culture; (B-F) 3D culture in which follicles are (B) embedded in a gel matrix, (C) enclosed into alginate beads, suspended in (D) hanging microdrops, (E) rotating wall vessels, and (F) orbiting test tubes or roller bottle systems. 
tadjody et al., 2013). The encapsulated cells displayed endocrine functions during 30 days of culture secreting 17-beta-estradiol, activin and inhibin in response to $\mathrm{FSH}$ and $\mathrm{LH}$.

Besides rodents, the alginate culture system has been tested in other species, including nonhuman primates and humans. Rhesus monkey secondary follicles were cultured encapsulated in alginate beads for up to 30 days maintaining their growth rate and steroidogenic function. Higher survival and growth rates were obtained by using $0.5-2 \%$ alginate concentration, higher compared to that used for the mouse, suggesting that different physical environments may be required for the growth of follicles from different species (Xu etal., 2009a,b;Hornick et al., 2012). Alginate hydrogels proved to sustain also the growth of human small preatral follicles maintaining their viability (Amorim et al., 2009) and steroidogenic function (Xu et al., 2009a).

Other biomaterials, both natural and synthetic, have been tested although none of them supported full-term development and are hereafter only briefly listed (for a more detailed review see Belli et al., 2012) hyaluronic acid (Desai et al., 2012), Matrigel (Hovatta et al., 1997, 1999; Oktem and Oktay, 2007: Xu et al., 2009a; Zhu et al., 2012), agarose (Huanmin and Yong, 2000; Mousset-Simeón et al., 2005; Fujihara et al., 2012) and polyethylene glycol (Shikanov et al., 2011a). In addition, a number of other techniques aimed at keeping the follicle 3D organization have been experimented, including hanging microdrops (Wycherley et al., 2004; Nation and Selwood, 2009), orbiting test tubes (Rowghani et al., 2004; Heise et al., 2005, 2009), rotating wall vessels (Rowghani et al., 2004 or roller bottle systems (Nation and Selwood, 2009) (Fig. 1), although with limited results.

\section{Conclusions and future directions}

The maintenance of the ovarian follicle 3D architecture, with its somatic epithelium surrounding the growing oocyte, has been attempted with a variety of procedures using several type of matrices with collagen and alginate being those most used and those that led to better results, including proof-of-concept of full-term development. Pioneer in its kind, these studies have projected the culture of the ovarian follicle into the realm of tissue engineering, a research field that has already acquired solid experimental principles and a systems biology view in the production of other tissues (Lanza et al., 2007, Guilak et al., 2014). To this regard, the future build out of a more robust 3D follicle culture protocol will necessarily need to take into account of those biophysical cues that, in vitro, act upon the follicle structure such as shear stress, compressive and tensional forces and the geometry of the culture microenvironment. Though never tested during follicle culture, these forces have been shown to be critical for the 3D organisation of other developmental processes and tissues, by inducing - via mechano-transduction - alterations to a specific cell status of force equilibrium (tensegrity) and triggering biochemical responses that lead to changes to the transcriptional profile and functional features (Wozniak and Chen, 2009; Miller and Davidson, 2013). A hurdle to the measure of these physical cues on ovarian follicles could be their small size, although, to this regard, significant technological improvements have been very recently made that allow their analysis even directly on the single cell. For example, a cantilever of an atomic force microscope has been used to quantitate the responses of a cultured cell to stretching and compressive forces locally applied (Watanabe-Nakayama et al., 2011) or to study the hardness (indicator of tensegrity) of single bacteria (Nakanishi et al., 2012). Also, a microfluidic mass sensor has been developed to measure the density (mass/volume) of single erythrocytes, allowing their selection into classes depending on their response to specific drug treatments (Grover et al., 2011). The possibility of taking measurements of these physical cues combined with the analysis of markers of the follicle developmental competence, such as the expression of specific transcripts, transcriptional programmes and epigenetics requirements could help the establishment of a more robust culture system. To this end, the use of integrative bioinformatics tools has recently provided new insights into the transcriptional and epigenomics programmes that act behind oocyte maturation and the process of folliculogenesis. Whole-genome transcriptional profiles are already available for human, mouse and cow oocytes (Adjaye, 2005; Huang and Wells, 2010: Assou et al., 2011; Diedrichs et al., 2012; Labreque and Sirard, 2014) and cumulus cells (Assou et al., 2008; van Montfoort et al., 2008; Ouandaogo et al., 2011; Vigone et al., 2013; Fragouli et al., 2014; $\mathrm{Xu}$ et al., 2014). Also, the epigenetic signature (i.e., DNA methylation and histone acetylation and methylation) of the female gamete has been described either for specific genome sequences using the traditional bisulfite conversion and immunofluorescence assays (Endo et al., 2005; Yeo et al., 2005; Hou et al., 2008; Kageyama et al., 2007; Liu et al., 2004; Racedo et al., 2009; Zuccotti et al., 2011; Denomme et al., 2012; Qiao et al., 2010; Pan et al., 2012; De La Fuente et al., 2004; Akiyama et al., 2004; Spinaci et al., 2004) or, for the whole genome, employing the reduced representation bisulfite sequencing (RRBS), a technique that couples the classical bisulfite conversion with the next generation sequencing technology (Smallwood et al., 2011: Tomizawa et al., 2012).

In summary, it is our belief that the future of in vitro 3D follicle culture lays in the cooperation of reproductive biologists with other research fields to build up a sound systems-biology approach towards a culture system that allows quantitative analyses and predictions. A more standardised culture protocol will allow to address, more precisely, issues that still remain open, such us the understanding of how oocytes and their surrounding cells are hierarchically organised and linked at both the cellular and molecular levels, what are the functional networks involved in this interaction, what is the role that mechano-transduction plays during follicle growth and how the follicle and its somatic and germ cell components react to the biophysical forces present in the culture system.

\section{Acknowledgements}

We thank the following organizations for support: MZ, FIL-University of Parma: SG and VM, FAR University of Pavia: WW and JA, the German Federal Ministry of Education and Research (BMBF grant number 0315717A) as partner of the ERASysBioPlus initiative supported under the EU ERA-NET Plus scheme in FP7 and Medical Faculty of Heinrich Heine University, Duesseldorf: FMand RB, Fondazione Cariplo (grant2008-2006), the Italian Ministry of Health ITALBIONET project: LF, INAIL 2010 Grant.

\section{References}

ABIR R, ROIZMAN P, FISCH B, NITKE S, OKON E, ORVIETO R, BEN RAFAEL Z (1999). Pilot study of isolated early human follicles cultured in collagen gels for 24 hours. Hum Reprod 14: 1299-1301.

ADJAYE J (2005). Whole-genome approaches for large-scale gene identification and expression analysis in mammalian preimplantation embryos. Reprod Fertil Dev 17: $37-45$ 
AKIYAMA T, KIM JM, NAGATA M, AOKI F (2004). Regulation of histone acetylation during meiotic maturation in mouse oocytes. Mol Reprod Dev 69: 222-227.

AMORIM CA, VAN LANGENDONCKT A, DAVID A, DOLMANS MM, DONNEZ J (2009). Survival of human pre-antral follicles after cryopreservation of ovarian tissue, follicular isolation and in vitro culture in a calcium alginate matrix. Hum Reprod 24: 92-99.

ANCHAN RM, GINSBURG ES (2010). Fertility concerns and preservation in younger women with breast cancer. Crit Rev Oncol Hematol 74: 175-92.

ASSOU S, BOUMELA I, HAOUZI D, ANAHORY T, DECHAUD H, DE VOS J, HAMAMAH S (2011). Dynamic changes in gene expression during human early embryo development from fundamental aspects to clinical applications. Hum Reprod Update 17: 272-90.

ASSOU S, HAOUZI D, MAHMOUD K, AOUACHERIAA, GUILLEMIN Y, PANTESCO V, RÈME T, DECHAUD H, DE VOS J, HAMAMAH S (2008), A non-invasive test for assessing embryo potential by gene expression profiles of human cumulus cells a proof of concept study. Mol Hum Reprod 14: 711-9.

BELLI M, VIGONE G, MERICO V, REDI CA, ZUCCOTTI M, GARAGNA S (2012). Towards a 3D culture of mouse ovarian follicles. Int J Dev Biol 56: 931-937.

COMBELLES CM, FISSORE RA, ALBERTINI DF, RACOWSKY C (2005). In vitro maturation of human oocytes and cumulus cells using a co-culture three-dimensional collagen gel system. Hum Reprod 20: 1349-1358.

DE LA FUENTE R, VIVEIROS MM, BURNS KH, ADASHI EY, MATZUK MM, EPPIG JJ (2004). Major chromatin remodeling in the germinal vesicle (GV) of mammalian oocytes is dispensable for global transcriptional silencing but required for centromeric heterochromatin function. Dev Biol 275: 447-458.

DENOMME MM, ZHANG L, MANN MR (2012). Single oocyte bisulfite mutagenesis. $J$ Vis Exp 64

DESAI N, ABDELHAFEZ F, CALABRO A, FALCONE T (2012). Three dimensional culture of fresh and vitrified mouse pre-antral follicles in a hyaluronan-based hydrogel: a preliminary investigation of a novel biomaterial for in vitro follicle maturation. Reprod Biol Endocrinol 10: 29.

DIEDRICHS F, MLODY B, MATZ P, FUCHS H, CHAVEZ L, DREWS K, ADJAYE J (2012) Comparative molecular portraits of human unfertilized oocytes and primordial germ cells at 10 weeks of gestation. Int J Dev Biol 56: 789-97.

ENDO T, NAITO K, AOKI F, KUME S, TOJO H (2005). Changes in histone modifications during in vitro maturation of porcine oocytes. Mol Reprod Dev 71: 123-128.

EPPIG JJ, SCHROEDER AC (1989). Capacity of mouse oocytes from preantral follicles to undergo embryogenesis and development to live young after growth, maturation, and fertilization in vitro. Biol Reprod 41: 268-276.

FRAGOULI E, LALIOTI MD, WELLS D (2014). The transcriptome of follicular cells biological insights and clinical implications for the treatment of infertility. Hum Reprod Update 20: 1-11.

FUJIHARA M, COMIZZOLI P, WILDT DE, SONGSASEN N (2012). Cat and dog primordial follicles enclosed in ovarian cortex sustain viability after in vitro culture on agarose gel in a protein-free medium. Reprod Domest Anim 47 Suppl 6: 102-108.

GOMES JE, CORREIA SC, GOUVEIA-OLIVEIRA A, CIDADÃO AJ, PLANCHA CE (1999). Three-dimensional environments preserve extracellular matrix compartments of ovarian follicles and increase FSH-dependent growth. Mol Reprod Dev 54: 163-172.

GROVER WH, BRYAN AK, DIEZ-SILVA M, SURESH S, HIGGINS JM, MANALIS SR (2011). Measuring single-cell density. Proc NatlAcad SciUSA. 108: 10992-10996.

GUILAK F, BUTLER DL, GOLDSTEIN SA, BAAIJENS FP. (2014). Biomechanics and mechanobiology in functional tissue engineering. J Biomech. 47: 1933-1940.

HEISE M, KOEPSEL R, RUSSELL AJ, MCGEE EA (2005). Calcium alginate microencapsulation of ovarian follicles impacts FSH delivery and follicle morphology. Reprod Biol Endocrinol 3: 47.

HEISE MK, KOEPSEL R, MCGEE EA, RUSSELL AJ (2009). Dynamic oxygen enhances oocyte maturation in long-term follicle culture. Tissue Eng Part $C$ Methods 15: 323-332.

HORNICK JE, DUNCAN FE, SHEA LD, WOODRUFF TK (2012). Isolated primate primordial follicles require a rigid physical environment to survive and grow in vitro. Hum Reprod 27: 1801-1810.

HOU J, LIU L, ZHANG J, CUI XH, YAN FX, GUAN H, CHEN YF, AN XR (2008). Epigenetic modification of histone 3 at lysine 9 in sheep zygotes and its relationship with DNA methylation. BMC Dev Biol 8: 60.
HOVATTA O, SILYE R, ABIR R, KRAUSZ T, WINSTON RM (1997). Extracellular matrix improves survival of both stored and fresh human primordial and primary ovarian follicles in long-term culture. Hum Reprod 12: 1032-1036.

HOVATTA O, WRIGHT C, KRAUSZ T, HARDY K, WINSTON RM (1999). Human primordial, primary and secondary ovarian follicles in long-term culture: effect of partial isolation. Hum Reprod 14: 2519-2524.

HUANG Z, WELLS D (2010). The human oocyte and cumulus cells relationship new insights from the cumulus cell transcriptome. Mol Hum Reprod 16: 715-25.

HUANMIN Z, YONG Z (2000). In vitro development of caprine ovarian preantral follicles. Theriogenology 54: 641-650.

JIN SY, LEI L, SHIKANOV A, SHEA LD, WOODRUFF TK (2010). A novel two-step strategy for in vitro culture of early-stage ovarian follicles in the mouse. Fertil Steril 93: 2633-2639.

KAGEYAMA S, LIU H, KANEKO N, OOGA M, NAGATAM, AOKI F (2007). Alterations in epigenetic modifications during oocyte growth in mice. Reproduction 133: 85-94.

KREEGER PK, DECK JW, WOODRUFF TK, SHEA LD (2006). The in vitro regulation of ovarian follicle development using alginate-extracellular matrix gels. Biomaterials 27: 714-723.

LABRECQUE R, SIRARD MA (2014). The study of mammalian oocyte competence by transcriptome analysis progress and challenges. Mol Hum Reprod 20: 103-16.

LANZA R, LANGER R, VACANTI J (2007). Principles of tissue engineering. Third edn,. Elsevier Academic Press, Burlington, MA, USA.

LI R, ALBERTINI DF (2013). The road to maturation somatic cell interaction and self-organization of the mammalian oocyte. Nat Rev Mol Cell Biol 14: 141-52.

LIU H, KIM JM, AOKI F (2004). Regulation of histone H3 lysine 9 methylation in oocytes and early pre-implantation embryos. Development 131: 2269-2280.

MA S, LIN H, MIAO Y, LIU X, WANG B, DAI J (2007). The effect of three-dimensional demineralized bone matrix on in vitro cumulus-free oocyte maturation. Biomaterials 28: 3198-3207.

MAINIGI MA, ORD T, SCHULTZ RM (2011). Meiotic and developmental competence in mice are compromised following follicle development in vitro using an alginatebased culture system. Biol Reprod 85: 269-276.

MEIROW D, HARDAN I, DOR J, FRIDMAN E, ELIZUR S, RA'ANANI H, SLYUSAREVSKY E, AMARIGLIO N, SCHIFF E, RECHAVI G et al.,2008). Searching for evidence of disease and malignant cell contamination in ovarian tissue stored from hematologic cancer patients. Hum Reprod 23: 1007-13.

MILLER CJ, DAVIDSON LA (2013). The interplay between cell signalling and mechanics in developmental processes. Nat Rev Genet 14: 733-744.

MOCHIDA N, AKATANI-HASEGAWA A, SAKA K, OGINO M, HOSODA Y, WADA R, SAWAI H, SHIBAHARA H (2013). Live births from isolated primary/early secondary follicles following a multistep culture without organ culture in mice. Reproduction 146: 37-47.

MOUSSET-SIMEÓN N, JOUANNET P, LE COINTRE L, COUSSIEU C, POIROT C (2005). Comparison of three in vitro culture systems for maturation of early preantral mouse ovarian follicles. Zygote 13: 167-175.

NAKANISHI K, KOGURE A, FUJII T, KOKAWA R, DEUCHI K (2012). Development of method for evaluating cell hardness and correlation between bacterial spore hardness and durability. $J$ Nanobiotechnology 7: 10-22.

NATION A, SELWOOD L (2009). The production of mature oocytes from adult ovaries following primary follicle culture in a marsupial. Reproduction 138: 247-255.

OKTEM O, OKTAY K (2007). The role of extracellular matrix and activin-A in in vitro growth and survival of murine preantral follicles. Reprod Sci 14: 358-366.

OUANDAOGO ZG, HAOUZI D, ASSOU S, DECHAUD H, KADOCH IJ, DE VOS J, HAMAMAH S (2011). Human cumulus cells molecular signature in relation to oocyte nuclear maturity stage. PLoS One 6: e27179.

PAN Z, ZHANG J, LI Q, LI Y, SHI F, XIE Z, LIU H (2012). Current advances in epigenetic modification and alteration during mammalian ovarian folliculogenesis. $J$ Genet Genomics 39: 111-123.

PANGAS SA, SAUDYE H, SHEA LD, WOODRUFF TK (2003). Novel approach for the three-dimensional culture of granulosa cell-oocyte complexes. Tissue Eng 9: 1013-1021.

PARRISH EM, SILETZA, XU M, WOODRUFF TK, SHEALD (2011). Gene expression in mouse ovarian follicle development in vivo versus an ex vivo alginate culture system. Reproduction 142: 309-318. 
QIAO J, CHEN Y, YAN LY, YAN J, LIU P, SUN QY (2010). Changes in histone methylation during human oocyte maturation and IVF- or ICSI-derived embryo development. Fertil Steril 93: 1628-1636.

RACEDO SE, WRENZYCKI C, LEPIKHOV K, SALAMONE D, WALTER J AND NIEMANN H (2009). Epigenetic modifications and related mRNA expression during bovine oocyte in vitro maturation. Reprod Fertil Dev 21: 738-748.

ROWGHANI NM, HEISE MK, MCKEEL D, MCGEE EA, KOEPSEL RR, RUSSELLAJ (2004). Maintenance of morphology and growth of ovarian follicles in suspension culture. Tissue Eng 10: 545-552.

SHIKANOV A, SMITH RM, XU M, WOODRUFF TK, SHEA LD (2011a). Hydrogel network design using multifunctional macromers to coordinate tissue maturation in ovarian follicle culture. Biomaterials 32: 2524-2531.

SHIKANOV A, XU M, WOODRUFF TK, SHEA LD (2011b). A method for ovarian follicle encapsulation and culture in a proteolytically degradable 3 dimensional system. J Vis Exp. 15 (49).

SHIKANOVA, XU M, WOODRUFFTK, SHEALD (2009). Interpenetrating fibrin-alginate matrices for in vitro ovarian follicle development. Biomaterials 30: 5476-5485.

SKORY RM, XU Y, LONNIE D, SHEA LD, WOODRUFF TK (2015). Engineering the ovarian cycle using in vitro follicle culture. Human Reprod. 30: 1386-1395.

SITTADJODY S, SAUL JM, JOO S, YOO JJ, ATALAA, OPARAEC (2013). Engineered multilayer ovarian tissue that secretes sex steroids and peptide hormones in response to gonadotropins. Biomaterials 34: 2412-2420.

SMALLWOOD SA, TOMIZAWA S, KRUEGER F, RUF N, CARLI N, SEGONDSPICHON A, SATO S, HATA K, ANDREWS SR, KELSEY G (2011). Dynamic $\mathrm{CpG}$ island methylation landscape in oocytes and preimplantation embryos. Nat Genet 43: 811-814

SPINACI M, SEREN E, MATTIOLI M (2004). Maternal chromatin remodeling during maturation and after fertilization in mouse oocytes. Mol Reprod Dev 69: 215-221.

TAGLER D, MAKANJI Y, ANDERSON NR, WOODRUFF TK, SHEA LD. (2013). Supplemented $\alpha$ MEM/F12-based medium enables the survival and growth of primary ovarian follicles encapsulated in alginate hydrogels. Biotechnol Bioeng 110: 3258-3268.

TOMIZAWAS, NOWACKA-WOSZUKJ, KELSEYG (2012). DNAmethylation establishment during oocyte growth mechanisms and significance. Int J Dev Bio/56:867-75

TORRANCE C, TELFER E, GOSDEN RG (1989). Quantitative study of the development of isolated mouse pre-antral follicles in collagen gel culture. $J$ Reprod Fertil 87: 367-374.

VAN MONTFOORT AP, GERAEDTS JP, DUMOULIN JC, STASSEN AP, EVERS JL, AYOUBI TA (2008). Differential gene expression in cumulus cells as a prognostic indicator of embryo viability a microarray analysis. Mol Hum Reprod 14: 157-68.
VANHOUTTE L, NOGUEIRAD, DUMORTIERF, DE SUTTERP (2009). Assessment of a new in vitromaturation system for mouse and human cumulus-enclosed oocytes: three-dimensional prematuration culture in the presence of a phosphodiesterase 3-inhibitor. Hum Reprod 24: 1946-1959.

VIGONE G, MERICO V, PRIGIONEA, MULAS F, SACCHIL, GABETTAM, BELLAZZ R, REDI CA, MAZZINI G, ADJAYE J et al.,2013). Transcriptome based identification of mouse cumulus cell markers that predict the developmental competence of their enclosed antral oocytes. BMC Genomics 14: 380.

WATANABE-NAKAYAMA T, MACHIDA S, HARADA I, SEKIGUCHI H, AFRIN R, IKA $A$ (2011). Direct detection of cellular adaptation to local cyclic stretching at the single cell level by atomic force microscopy. Biophys J 100: 564-572.

WEST ER, XU M, WOODRUFF TK, SHEA LD (2007). Physical properties of alginate hydrogels and their effects on in vitro follicle development. Biomaterials 28: $4439-4448$

WOZNIAK MA, CHEN CS (2009). Mechanotransduction in development a growing role for contractility. Nat Rev Mol Cell Biol 10: 34-43.

WYCHERLEY G, DOWNEY D, KANE MT, HYNES AC (2004). A novel follicle culture system markedly increases follicle volume, cell number and oestradiol secretion. Reproduction 127: 669-677.

XU M, BARRETT SL, WEST-FARRELL E, KONDAPALLI LA, KIESEWETTER SE, SHEA LD, WOODRUFF TK (2009a). In vitro grown human ovarian follicles from cancer patients support oocyte growth. Hum Reprod 24: 2531-2540.

XU M, KREEGER PK, SHEA LD, WOODRUFF TK (2006b). Tissue-engineered follicles produce live, fertile offspring. Tissue Eng 12: 2739-2746.

XU M, WESTE, SHEALD, WOODRUFF TK (2006a). Identification of a stage-specific permissive in vitro culture environment for follicle growth and oocyte development Biol Reprod 75: 916-923.

XU M, WEST-FARRELL ER, STOUFFER RL, SHEA LD, WOODRUFF TK, ZELINSK MB (2009b). Encapsulated three-dimensional culture supports development o nonhuman primate secondary follicles. Biol Reprod 81: 587-594.

XUX, CHEND, ZHANG Z, WEIZ, CAOY. Molecular Signature in Human Cumulus Cells Related to Embryonic Developmental Potential. (2014). Reprod Sci. 22: 173-80.

YEO S, LEE KK, HAN YM AND KANG YK (2005). Methylation changes of lysine 9 of histone $\mathrm{H} 3$ during preimplantation mouse development. Mol Cells 20: 423-428.

ZHU HY, WANG JX, TONG XM, XU WH, JIANG LY, JING XY, YANG LY, ZHOU F ZHANG SY (2012). Three-dimensional cultures of human endometrial cells on Matrigel mimic in vivo morphology. Chin Med J 125: 863-868.

ZUCCOTTI M, MERICO V, CECCONI S, REDI CAAND GARAGNA S (2011). What does it take to make a developmentally competent mammalian egg? Hum Reprod Update 17: 525-540. 


\section{Further Related Reading, published previously in the Int. J. Dev. Biol.}

\section{Towards a 3D culture of mouse ovarian follicles}

Martina Belli, Giulia Vigone, Valeria Merico, Carlo Alberto Redi, Maurizio Zuccotti and Silvia Garagna Int. J. Dev. Biol. (2012) 56: 931-937

http://dx.doi.org/10.1387/ijdb.120175mz

OCT4 and the acquisition of oocyte developmental competence during folliculogenesis Maurizio Zuccotti, Valeria Merico, Martina Belli, Francesca Mulas, Lucia Sacchi, Blaz Zupan, Carlo Alberto Redi, Alessandro Prigione, James Adjaye, Riccardo Bellazzi and Silvia Garagna Int. J. Dev. Biol. (2012) 56: 853-858

http://dx.doi.org/10.1387/ijdb.120174mz

Genome organization and epigenetic marks in mouse germinal vesicle oocytes Amelie Bonnet-Garnier, Prisca Feuerstein, Martine Chebrout, Renaud Fleurot, Habib-Ullah Jan, Pascale Debey and Nathalie Beaujean

Int. J. Dev. Biol. (2012) 56: 877-887

http://dx.doi.org/10.1387/ijdb.120149ab

Oocyte ageing and its cellular basis Ursula Eichenlaub-Ritter

Int. J. Dev. Biol. (2012) 56: 841-852

http://dx.doi.org/10.1387/ijdb.120141ue

Factors engaged in reactivation of DNA replication in the nuclei of growing mouse oocytes introduced into the cytoplasm of parthenogenetic one-cell embryos

Ewa Borsuk and Renata Czolowska

Int. J. Dev. Biol. (2010) 54: 21-31

http://dx.doi.org/10.1387/ijdb.092873eb

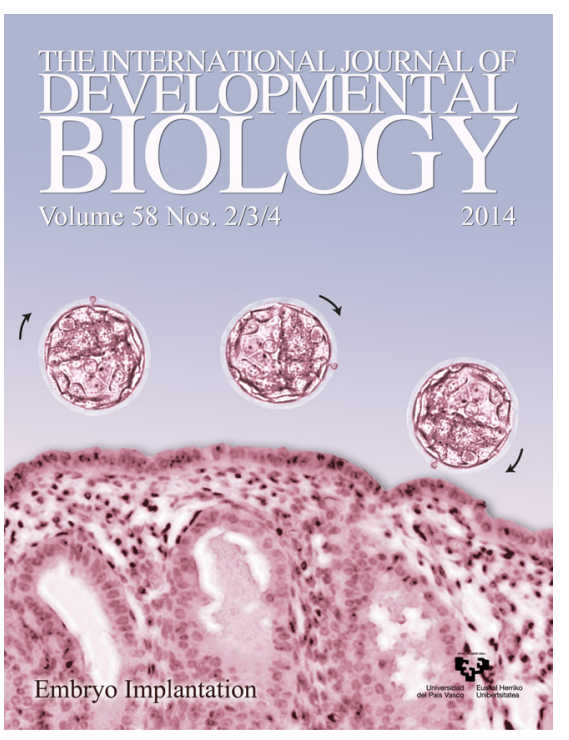

5 yr ISI Impact Factor $(2013)=2.879$
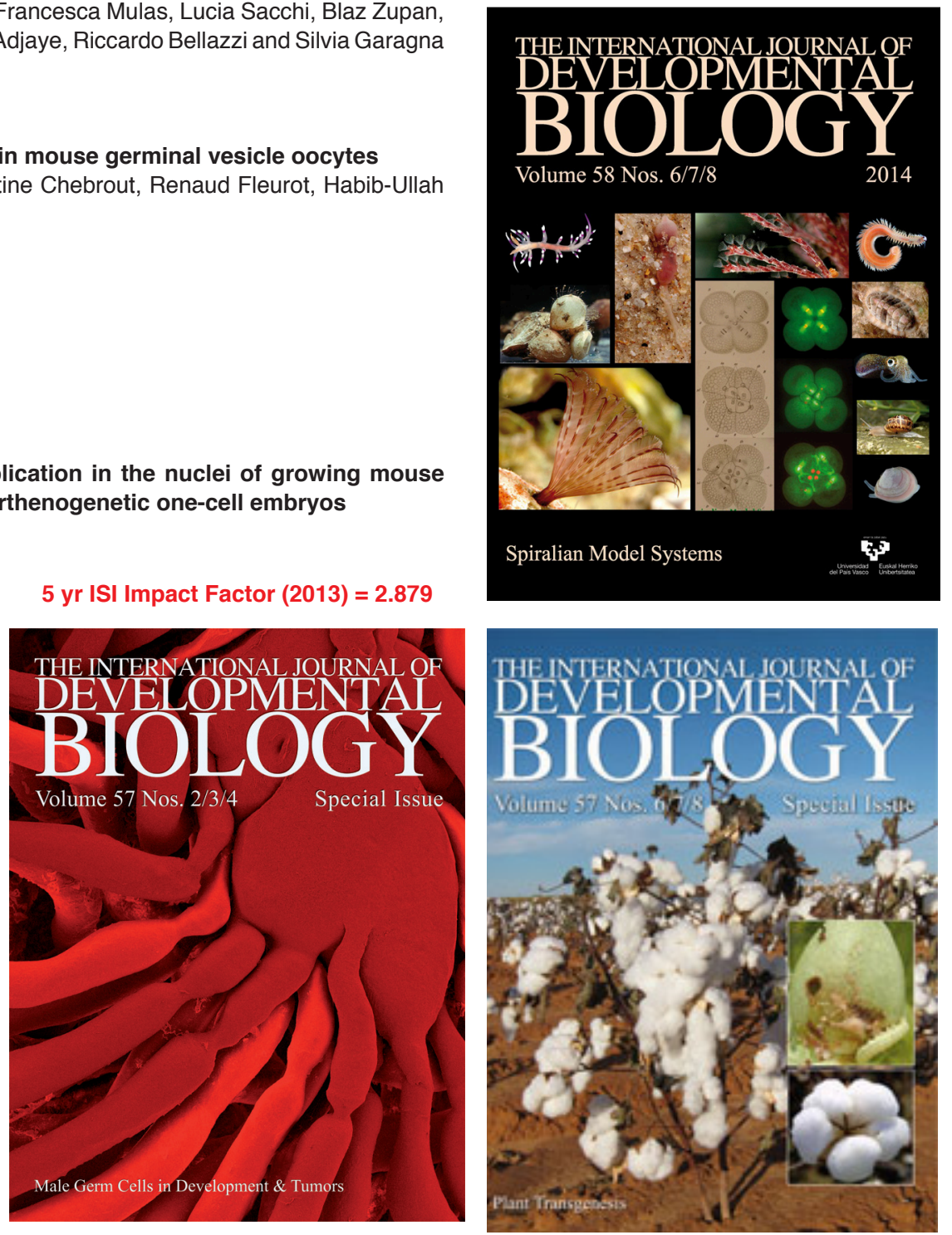